\title{
Socioeconomic health inequalities among a nationally representative sample of Danish adolescents: the role of different types of social relations
}

\author{
P Due, J Lynch, B Holstein, J Modvig
}

See end of article for authors' affiliations

Correspondence to Dr P Due, Department of Social Medicine, Institute of Public Health, University of Copenhagen, Blegdamsvej 3, DK-2200 Copenhagen Denmark;

p.due@pubhealth.ku.dk

Accepted for publication 21 February 2003

\begin{abstract}
Study objective: To investigate the role of different types of social relations in adolescent health inequalities.

Design: Cross sectional study. Measures included family social class, indices of social relations to parents, friends, teachers, and school.

Setting: Random sample of 55 schools in Denmark.

Participants: Nationally representative sample of 5205 students from grades 5, 7, and 9 .

Main outcome measures: Self reported physical and psychological symptoms.

Results: Adolescents from families of lower socioeconomic position reported more physical and psychological symptoms. This ranged from $40 \%$ increased odds for multiple physical symptoms among less advantaged girls, to $90 \%$ increased odds of multiple psychological symptoms for less advantaged boys. Relationships with friends or teachers showed small social class differences, while strong and consistent social class differences were found in the ways adolescents reported their own and their parents relations to school. For example, girls from families of lower socioeconomic position were more than four times as likely to report their parents unwilling to attend school meetings (odds ratio $=4.54$, $95 \%$ confidence intervals: 2.68 to 7.69 ). Poorer relations with parents, peers, teachers, and school were all associated with worse health. Patterns of parent-child relations with the school were the greatest contributors to socioeconomic differences in physical and psychological symptoms.

Conclusions: The school is one of the first important social institutions directly experienced by children and socioeconomic differences in how adolescents and their parents relate to the school may be part of the cascade of early life influences that can lead to later social and health disadvantage.
\end{abstract}

foct here have been comparatively few studies that have focused specifically on socioeconomic differences in adolescent health. Some have shown health inequalities among adolescents to be smaller than those observed at younger or older ages, ${ }^{1-3}$ while others have reported virtually no socioeconomic health differences. ${ }^{4-9}$ Health inequalities in later life reflect a broad range of accumulated lifetime exposures, ${ }^{10}{ }^{11}$ but this is much less the case in adolescence, partly because socioeconomic differences in such things as smoking, diet, and environmental exposures have had little time to overtly express themselves pathologically. Thus, it is less clear what factors might help us understand socioeconomic inequalities in adolescent health.

In general, adolescents are biologically robust, with low morbidity and mortality. Nevertheless, the potential importance of physical and psychological symptoms as meaningful health outcomes in this age group should not be overlooked. ${ }^{12}$ For instance, self reported symptoms can play a part in the diagnosis and management of conditions like asthma, ${ }^{13}$ and are related to levels of prescribed and over the counter medication use. ${ }^{14}$ There is evidence that rates of such medication use by adolescents for symptoms like head and stomach ache have increased in Denmark since $1988^{15}$ and new research shows this to be the case in several other Western European countries. ${ }^{16}$ In addition, there have been reported increases in psychological symptoms of general malaise, depression, and growing concerns about adolescent suicide. ${ }^{17}{ }^{18}$ Furthermore, experience of symptoms in childhood may be related to factors that also track into adulthood. For instance, a recent paper has shown that children with headache are at an increased risk of recurring headache, multiple physical symptoms, and psychiatric morbidity in adulthood. ${ }^{19} 20$
Late childhood and early adolescence is an important stage of the lifecourse, partly because it represents the transition from a more circumscribed, family centred environment, to a broader environment more open to influences of peers and non-family members. Control over behaviour, psychological orientation, styles of self presentation, and social interaction shift from parents to child. Adolescents go through the challenge of developing their identity as an independent individual, while the structure and functions of their social relations undergo rapid change. This combination of changes and challenges may mean that adolescents are particularly susceptible to influences from various aspects of social relations with family, friends, teachers, school, and the broader environment that are all important influences on successfully building an independent identity and navigating this difficult transition into the wider world. The public health significance of particular types of social experiences among young people is evidenced in recent studies that showed bullying at school affected physical and mental health. ${ }^{21-24}$ Other studies have suggested how different sorts of social interactions can influence adolescent depression, aggression, and suicidal ideation.$^{25-27}$ Moreover, some of these early life experiences may have long term implications for health in adulthood. ${ }^{28}$ Social relations are probably important to adolescent health in general but we are not aware of any studies on the contribution of social relations to adolescent health inequalities. Thus, the purpose of this study was to examine socioeconomic differences in adolescent health and the role that different aspects of social relations played in understanding these socioeconomic differences. 


\section{METHODS}

We used data from a nationally representative cross sectional survey-the Danish contribution to the 1997/1998 WHO international collaborative study-health behaviour in school-aged children (HBSC). ${ }^{29}$ The study included 5205 students aged 11 , 13 , and 15 years, drawn from a random sample of students in grades 5, 7, and 9 in 55 schools in Denmark. Response rate was $99 \%$ of the students contacted and $88 \%$ of the target population. Data were collected by a standardised questionnaire in the classroom after instruction from the teacher.

The following measurements were used.

\section{Socioeconomic position}

As a measure of socioeconomic position we used social class. Family social class was measured by standard coding of the highest ranking parental occupation using the Danish Social Class Classification, which is similar to the British registrar general's classification I-V. We included economically inactive as group VI of the socioeconomic postion. We combined social class I-II into socioeconomic group I (high), social class III-IV into group II and social class V and economically inactive into group III (low). Use of other coding schemes for family social class, like father's social class or mother's social class, did not change the conclusions of the study. Twelve per cent of the sample was excluded because of missing or insufficient information. The missing data showed no gender difference, but there were more missing data among the youngest children ( $17 \%$ among 11 year olds, $12 \%$ among 13 years olds, and $7 \%$ among 15 year olds). These rates of missing information are somewhat lower than other studies of adolescents, ${ }^{3}$ and the resulting social class distribution corresponded closely to age specific Danish national figures. ${ }^{2}$

\section{Social relations}

Social relations was conceived in a general framework as having several dimensions. Relations with parents were assessed with questions regarding (1) structural living arrangementswhether the child was living with one or two adults; (2) emotional support in terms of communication with parentsthe ease of talking with father/mother about things that really bother you (difficult with both parents compared with easy with at least one parent); and (3) aspects of parent-child relations in regard to school-including, too high parental expectations of performance at school (agree compared with disagree/neither), willingness of parents to help with problems at school, willingness of parents to come to meetings at school and encouragement from parents to do well at school. The three last items dichotomised at sometimes/never compared with always/often. All analyses were adjusted for living with less than two adults. A composite measure of poor relations with parents was made by summing the $0 / 1$ responses to the remaining five questions concerning emotional support and parent-child relations to school. A score of 4 or more was considered as indicating poorer relations with parents.

Relations with friends were measured by questions on the: (1) number of close friends (none or one compared with two or more); (2) frequency of contact out of school (once a week or less compared with more than once a week); (3) ease of talking with same sex friends about things that really bother you; and (4) ease of talking with opposite sex friends about things that really bother you. The last two items dichotomised at difficult/very difficult compared with easy/very easy. A composite measure of relations with friends was made by summing the 0/1 responses of all four items. A score of 3 or more indicated poorer relations with friends.

Relations with teachers were measured by questions on: (1) whether adolescents perceived they were fairly treated by teachers; and (2) getting help from teachers when needed. Items were dichotomised at neither strongly agree compared with agree/strongly agree and a composite measure of relations with teachers was made by summing these questions. A score of 1 or more was considered as indicating poorer relations with teachers.

Relations to school were measured by questions about: (1) overly strict treatment of students (strongly agree/agree compared with neither strongly disagree); (2) perceptions of the fairness of school rules (neither strongly disagree compared with agree/strongly agree); (3) sense of belonging in the school (neither strongly disagree compared with agree/ strongly agree); (4) feeling safe at school (sometimes/never compared with often/always); and (5) experiences of being bullied at school (once a week or more compared with sometimes/never). A composite measure of connections to school was made by summing the five questions. A score of 3 or more indicated poorer connections to school.

\section{Health status}

There were five physical symptoms: (1) headache, (2) stomach ache, (3) back pain, (4) dizziness, and (5) difficulties in getting to sleep. These were all measured in five categories ranging from "about every day" to "rarely or never". Each item was dichotomised into weekly symptoms compared with less. There were seven psychological symptoms: three items-"feeling low", "irritable/bad temper", and "feeling nervous"-were all scored "about every day" to "rarely or never" and were dichotomised into weekly symptoms compared with less. Four items-“feeling left out of things, "feeling helpless", "feeling self confident", and "feeling lonely" - were scored as "always/ often compared with sometimes/never". Separate composite measures of physical and psychological symptoms were created by summing the total number of relevant symptoms (five physical/seven psychological). These scales were dichotomised at more than two symptoms. Confirmatory factor analysis subsequently showed that these items divided into two factors corresponding to physical and psychological symptoms. This accords with another factor analysis of the same measures in the comparable Norwegian HBSC sample that showed these scales measure two empirically different constructs: physical and psychological symptoms. ${ }^{30}$ These measures have been used in five waves of cross sectional HBSC surveys since 1984, last in 1998 in 28 European and North American countries.

We used multivariate logistic regression to examine sex specific associations between socioeconomic position, different aspects of social relations and self reported physical and psychological symptoms. We first modelled socioeconomic differences in aspects of social relations-both separately and as combined indices-(table 2). Then we modelled how aspects of social relations-both separately and as combined indiceswere associated with physical and psychological symptoms (table 3). Finally, in table 4 we modelled the simultaneous effects of socioeconomic position and social relations on physical and psychological symptoms. Preliminary analyses showed few differences in the patterns of associations by age, so age adjusted results are presented. Sensitivity analyses (not shown) were conducted and our results are robust to changes in the definition and types of exposure categories for social class (highest social class compared with mother's or father's); to changes in the definitions of exposure categories for social relations variables ( that is, we find similar results by dichotomising at extreme values like strongly disagree compared with disagree/strongly agree and with alternative frequencies like once a week or less/2-3 days compared with 4-5 times a week), and to changes in the definitions of the symptom outcomes (that is, patterns of findings are similar whether they are based on comparisons of the extreme categories "never compared with everyday", or "never/rarely compared with everyday). All analyses were performed using SAS Version 6.12.

\section{RESULTS}

Table 1 shows the sex specific prevalence of aspects of physical and psychological symptoms, social relations, and the 
Table 1 Physical symptoms, psychological symptoms, socioeconomic position, and social relations by gender among $11,13$, and 15 year olds in Denmark, 1998 ( $n=5205)$

\begin{tabular}{|c|c|c|c|c|c|}
\hline & \multicolumn{2}{|c|}{ Girls $(n=2624)$} & \multicolumn{2}{|c|}{ Boys $(n=2581)$} & \multirow[b]{2}{*}{$\mathrm{p}$ Value } \\
\hline & $\mathrm{n}$ & $\%$ & $\mathrm{n}$ & $\%$ & \\
\hline \multicolumn{6}{|l|}{ Physical symptoms (at least weekly) } \\
\hline headache & 820 & 32 & 484 & 19 & $<0.001$ \\
\hline stomach ache & 454 & 18 & 222 & 9 & $<0.001$ \\
\hline back pain & 529 & 21 & 513 & 21 & 0.761 \\
\hline feel dizzy & 443 & 17 & 292 & 12 & $<0.001$ \\
\hline difficulties in getting to sleep & 927 & 36 & 807 & 32 & $<0.001$ \\
\hline Combined physical symptoms index (having $3+$ ) & 510 & 19 & 340 & 13 & $<0.001$ \\
\hline \multicolumn{6}{|l|}{ Psychological symptoms (at least weekly) } \\
\hline feel sad & 1008 & 40 & 439 & 18 & $<0.001$ \\
\hline irritable / bad temper & 1384 & 54 & 1086 & 43 & $<0.001$ \\
\hline nervous & 709 & 28 & 531 & 21 & $<0.001$ \\
\hline feel left out of things & 155 & 6 & 109 & 4 & 0.007 \\
\hline feel helpless & 101 & 4 & 83 & 3 & 0.232 \\
\hline not confident in myself & 914 & 36 & 503 & 20 & $<0.001$ \\
\hline feel lonely & 245 & 9 & 98 & 4 & $<0.001$ \\
\hline Combined psychological symptoms index (having $3+$ ) & 817 & 31 & 407 & 16 & $<0.001$ \\
\hline \multicolumn{6}{|l|}{ Socioeconomic position } \\
\hline I (high) top/medium level white collar, large/medium scale self employed & 678 & 29 & 662 & 29 & 0.780 \\
\hline II (middle) lower level white collar, small scale self employed, skilled manual & 1193 & 51 & 1195 & 53 & 0.175 \\
\hline $\begin{array}{l}\text { III (low) unskilled manual, economically inactive, live from social welfare } \\
\text { benefits }\end{array}$ & 460 & 20 & 390 & 17 & 0.039 \\
\hline \multicolumn{6}{|l|}{ Relations with parents and friends } \\
\hline \multicolumn{6}{|l|}{ Parents: } \\
\hline live with only one adult & 485 & 20 & 475 & 21 & 0.777 \\
\hline difficult to talk with either parent about things that really bothers & 557 & 21 & 507 & 20 & 0.157 \\
\hline parents expect too much from me in school & 581 & 23 & 848 & 34 & $<0.001$ \\
\hline parents not ready to help with problems at school & 197 & 8 & 170 & 7 & 0.216 \\
\hline parents not ready to come to meetings at school & 160 & 6 & 169 & 7 & 0.473 \\
\hline parents don't encourage me to do well at school & 363 & 14 & 349 & 14 & 0.793 \\
\hline Combined parental relations index (having 4+) & 443 & 17 & 460 & 18 & 0.313 \\
\hline \multicolumn{6}{|l|}{ Friends: } \\
\hline difficult to talk with friends of same sex about things that really bothers & 491 & 19 & 776 & 31 & $<0.001$ \\
\hline difficult to talk with friends of opposite sex about things that really bothers & 1688 & 66 & 1499 & 61 & $<0.001$ \\
\hline less than two close friends & 248 & 9 & 210 & 8 & 0.101 \\
\hline seldom with friends just after school & 785 & 30 & 619 & 24 & $<0.001$ \\
\hline Combined friend relations index (having $3+$ ) & 869 & 34 & 935 & 37 & 0.010 \\
\hline \multicolumn{6}{|l|}{$\begin{array}{l}\text { Relations with teachers and connection to school } \\
\text { Teachers: }\end{array}$} \\
\hline teachers don't treat students fairly & 1188 & 46 & 1099 & 44 & 0.062 \\
\hline teachers don't help me if I need extra help & 818 & 32 & 684 & 27 & $<0.001$ \\
\hline Combined teacher relations index (having $1+$ ) & 553 & 22 & 442 & 18 & $<0.001$ \\
\hline \multicolumn{6}{|l|}{ School: } \\
\hline pupils are treated too strictly & 234 & 9 & 515 & 20 & $<0.001$ \\
\hline the rules at our school are not fair & 1223 & 47 & 1194 & 47 & 0.807 \\
\hline don't feel safe at school & 788 & 30 & 685 & 27 & 0.008 \\
\hline don't feel I belong at my school & 1558 & 61 & 1573 & 62 & 0.327 \\
\hline are bullied weekly or more & 202 & 8 & 227 & 9 & 0.147 \\
\hline Combined school connections index (having $3+$ ) & 546 & 21 & 617 & 24 & 0.007 \\
\hline
\end{tabular}

distribution of family socioeconomic postion. There is a high prevalence of reported physical symptoms in these age groups. Some $19 \%$ of girls and $13 \%$ of boys reported more than two weekly physical symptoms. Difficulties getting to sleep, headache, and back pain were the most prevalent $(34 \%, 26 \%$, and $21 \%$ respectively). The prevalence of having more than two psychological symptoms was higher among girls than boys $(31 \% v 16 \%, \mathrm{p}<0.001)$. The higher prevalence among girls of feeling sad and lack of self confidence accounted for most of the gender differences found in psychological symptoms. The data on social relations showed that large proportions of students have difficulties in their relations with parents, friends, teachers, and school. More boys report too high expectations from parents (34\% v 23\% among girls, $\mathrm{p}<0.001)$ and difficulties talking about problems with friends of same sex $(31 \% \mathrm{v}$
$19 \%$ among girls, $\mathrm{p}<0.001)$, and more girls report that they do not get help from the teacher, when they need it (32\% v27\%, $\mathrm{p}<0.001$ ), but most other aspects of social relations show no strong sex differences.

\section{Socioeconomic patterns of social relations}

Table 2 shows socioeconomic patterns of social relations. There were no significant social differences in the ability of adolescents to talk with either parent about things that really bothered them. This appears to reflect a lack of socioeconomic differentiation in the emotional support and informal communication between parents and adolescents. In contrast, there were strong socioeconomic differences for how adolescents related to their parents in terms of school. For instance, female adolescents from poorer families were 4.5 times (95\% 
Table 2 Age adjusted odds ratios $(95 \% \mathrm{Cl})$ for poor relations with parents, friends and teachers and connection to school by parents' socioeconomic position (socioeconomic group III (low) compared with I (high)) among 5205 11, 13, and 15 year olds in Denmark, 1998

\begin{tabular}{|c|c|c|c|c|}
\hline & \multicolumn{2}{|l|}{ Girls } & \multicolumn{2}{|l|}{ Boys } \\
\hline & OR & $95 \% \mathrm{Cl}$ & OR & $95 \% \mathrm{Cl}$ \\
\hline \multicolumn{5}{|l|}{ Relations with parents and friends } \\
\hline \multicolumn{5}{|l|}{ Parents: } \\
\hline live with only one adult & 1.32 & 0.98 to 1.78 & 1.45 & 1.05 to 2.00 \\
\hline difficult to talk with either parent about things that really bothers & 1.33 & 0.99 to 1.78 & 1.27 & 0.93 to 1.74 \\
\hline parents expect too much from me in school & 1.56 & 1.17 to 2.07 & 1.36 & 1.04 to 1.78 \\
\hline parents not ready to help with problems at school & 3.14 & 1.94 to 5.09 & 2.50 & 1.53 to 4.09 \\
\hline parents not ready to come to meetings at school & 4.54 & 2.68 to 7.69 & 1.98 & 1.20 to 3.26 \\
\hline parents don't encourage me to do well at school & 2.58 & 1.83 to 3.64 & 1.58 & 1.09 to 2.29 \\
\hline Combined parental relations index & 2.26 & 1.64 to 3.12 & 2.01 & 1.46 to 1.78 \\
\hline \multicolumn{5}{|l|}{ Friends: } \\
\hline difficult to talk with friends of same sex about things that really bothers & 1.22 & 0.89 to 1.68 & 1.25 & 0.95 to 1.64 \\
\hline difficult to talk with friends of opposite sex about things that really bothers & 1.04 & 0.80 to 1.36 & 0.94 & 0.72 to 1.23 \\
\hline less than two close friends & 1.15 & 0.78 to 1.71 & 1.02 & 0.66 to 1.58 \\
\hline seldom with friends just after school & 1.43 & 1.10 to 1.84 & 0.99 & 0.74 to 1.33 \\
\hline Combined friend relations index & 1.23 & 0.95 to 1.58 & 0.95 & 0.73 to 1.23 \\
\hline \multicolumn{5}{|l|}{ Relations with teachers and connection to school } \\
\hline \multicolumn{5}{|l|}{ Teachers: } \\
\hline teachers don't help me if I need extra help & 1.04 & 0.80 to 1.36 & 1.09 & 0.83 to 1.44 \\
\hline teachers don't treat students fairly & 1.51 & 1.19 to 1.93 & 1.58 & 1.22 to 2.05 \\
\hline Combined teacher relations index & 1.26 & 0.93 to 1.71 & 1.48 & 1.07 to 2.03 \\
\hline \multicolumn{5}{|l|}{ School: } \\
\hline pupils are treated too strictly & 1.78 & 1.19 to 2.66 & 2.04 & 1.48 to 2.81 \\
\hline the rules at our school are not fair & 1.52 & 1.19 to 1.93 & 1.65 & 1.28 to 2.13 \\
\hline don't feel safe at school & 2.22 & 1.71 to 2.89 & 2.27 & 1.70 to 3.01 \\
\hline don't feel I belong at my school & 1.55 & 1.21 to 1.99 & 1.94 & 1.48 to 2.54 \\
\hline are bullied & 2.31 & 1.43 to 3.74 & 2.21 & 1.44 to 3.39 \\
\hline Combined school connections index & 2.51 & 1.87 to 3.37 & 2.45 & 1.82 to 3.28 \\
\hline
\end{tabular}

CI 2.68 to 7.69 ) more likely to report their parents not willing to come to school meetings. There were no consistent socioeconomic differences in relations with friends, but strong associations emerged with respect to socioeconomic postion and every aspect of adolescent perceptions of their school. For instance, adolescents from families of low socioeconomic position were more than twice as likely to report not feeling safe at school. (OR=2.22 (95\% CI 1.71 to 2.89$)$ for girls and $\mathrm{OR}=2.27$ (95\% CI 1.70 to 3.01 ) for boys). Overall, adolescents from homes of lower socioeconomic position were more than twice as likely to report poorer connections to their schools.

\section{Social relations and health}

Table 3 shows that living with a lone parent was not associated with symptoms. Relations with parents were associated with both kinds of symptoms, including every item concerning support for school related activities. For instance, female adolescents reporting less help from parents with problems at school were at more than threefold risk of three or more weekly psychological symptoms (OR=3.56 ( $95 \%$ CI 2.64 to $4.80)$ ). For both sexes, lack of good relationships with friends was more strongly associated with psychological than physical symptoms. Relations with teachers were modestly associated with health outcomes in both sexes. Items measuring connections to school showed the strongest associations with both health outcomes. The strongest associations with health were seen for not feeling safe at school (OR=3.64 (95\% CI 3.04 to 4.35 ) for girls, $\mathrm{OR}=3.79$ (95\% CI 3.01 to 4.76 ) for boys) and being bullied (OR=4.44 (95\% CI 3.28 to 6.00$)$ for girls, $\mathrm{OR}=5.09$ ( $95 \%$ CI 3.80 to 6.81 ) for boys).

\section{Socioeconomic position, social relations, and health}

Table 4 shows that adolescents from families of low socioeconomic position reported more physical and psychological symptoms. This ranged from about $40 \%$ increased odds for multiple physical symptoms among less advantaged girls ( $\mathrm{OR}=$ 1.43 ( $95 \%$ CI 1.07 to 1.91 )), to more than $90 \%$ increased odds of multiple psychological symptoms for less advantaged boys $(\mathrm{OR}=1.94$ (95\% CI 1.39 to 2.70$))$. Models 2, 3, 4, and 5 show the effect of adjusting for different aspects of social relations on socioeconomic differences in health. Social differences in adolescent health were reduced but remained after adjustment for parental relations, which was itself strongly associated with symptoms (Model 2). Social differences for symptoms in girls were unaffected by adjustment for friend relations, whereas they were somewhat reduced among boys. Friend relations were only associated with psychological symptoms (Model 3). Socioeconomic differences for symptoms in girls were unaffected by adjustment for teacher relations, whereas they were somewhat reduced among boys. Teacher relations were strongly associated with symptoms (Model 4). Socioeconomic differences in adolescent health were most attenuated by adjustment for school relations, and these also remained strongly independently associated with symptoms (Model 5). Finally, Model 6 shows that there were essentially no or at least quite small socioeconomic differences in reports of adolescent symptoms after simultaneous adjustment for all aspects of social relations, but the most important were the aspects related to the functioning of the parent-child-school triad (that is, parental relations and school relations).

\section{DISCUSSION}

We found associations between lower family socioeconomic position and both physical and psychological symptoms among 11-15 year old Danes. These health inequalities were statistically explained by different socioeconomic patterns of parental support for school, and through adolescents' perceptions of their relations to school in terms of institutional rules, 
Table 3 Age adjusted odds ratios $(95 \% \mathrm{Cl})$ for physical and psychological symptoms by social relations and connections to school among 520511,13 , and 15 year olds in Denmark, 1998

\begin{tabular}{|c|c|c|c|c|c|c|c|c|}
\hline & \multicolumn{4}{|l|}{ Girls } & \multicolumn{4}{|l|}{ Boys } \\
\hline & \multicolumn{2}{|c|}{ Physical symptoms* } & \multicolumn{2}{|c|}{ Psychological symptoms $†$} & \multicolumn{2}{|c|}{ Physical symptoms* } & \multicolumn{2}{|c|}{ Psychological symptoms $\uparrow$} \\
\hline & OR & $95 \% \mathrm{Cl}$ & OR & $95 \% \mathrm{Cl}$ & OR & $95 \% \mathrm{Cl}$ & OR & $95 \% \mathrm{Cl}$ \\
\hline \multicolumn{9}{|l|}{ Parents: } \\
\hline live with only one adult & 1.16 & 0.91 to 1.49 & 1.15 & 0.93 to 1.42 & 1.33 & 1.00 to 1.77 & 1.05 & 0.80 to 1.38 \\
\hline $\begin{array}{l}\text { difficult to talk with either parent about } \\
\text { things that really bothers }\end{array}$ & 1.86 & 1.49 to 2.31 & 2.37 & 1.96 to 2.88 & 1.46 & 1.12 to 1.92 & 2.02 & 1.58 to 2.58 \\
\hline $\begin{array}{l}\text { parents expect too much from me in } \\
\text { school }\end{array}$ & 1.65 & 1.32 to 2.06 & 1.67 & 1.37 to 2.02 & 1.49 & 1.18 to 1.89 & 1.56 & 1.25 to 1.95 \\
\hline $\begin{array}{l}\text { parents not ready to help with } \\
\text { problems at school }\end{array}$ & 2.82 & 2.08 to 3.83 & 3.56 & 2.64 to 4.80 & 2.06 & 1.40 to 3.01 & 2.08 & 1.44 to 3.01 \\
\hline $\begin{array}{l}\text { parents not ready to come to meetings } \\
\text { at school }\end{array}$ & 2.12 & 1.50 to 2.99 & 2.19 & 1.58 to 3.02 & 1.18 & 0.76 to 1.83 & 1.19 & 0.78 to 1.82 \\
\hline $\begin{array}{l}\text { parents don't encourage me to do well } \\
\text { at school }\end{array}$ & 1.96 & 1.53 to 2.53 & 2.45 & 1.95 to 3.07 & 1.57 & 1.16 to 2.13 & 1.92 & 1.45 to 2.55 \\
\hline Combined parental relations index & 2.45 & 1.95 to 3.08 & 3.13 & 2.54 to 3.86 & 1.85 & 1.41 to 2.42 & 2.25 & 1.75 to 2.90 \\
\hline \multicolumn{9}{|l|}{ Friends: } \\
\hline about things that really bothers & 1.47 & 1.10101 .08 & 2.10 & 1.70 10 2.05 & 1.10 & 0.80 to 1.42 & $1.3 /$ & 1.23 to 1.91 \\
\hline $\begin{array}{l}\text { difficult to talk with friends of opposite } \\
\text { sex about things that really bothers }\end{array}$ & 0.88 & 0.71 to 1.09 & 1.37 & 1.14 to 1.66 & 0.75 & 0.59 to 0.95 & 1.13 & 0.89 to 1.43 \\
\hline less than two close friends & 1.12 & 0.81 to 1.54 & 2.50 & 1.92 to 3.26 & 1.51 & 1.04 to 2.19 & 2.06 & 1.48 to 2.87 \\
\hline seldom with friends just after school & 0.93 & 0.75 to 1.15 & 1.64 & 1.37 to 1.96 & 0.95 & 0.72 to 1.24 & 1.66 & 1.32 to 2.10 \\
\hline Combined friend relations index & 1.10 & 0.90 to 1.36 & 1.99 & 1.67 to 2.37 & 1.05 & 0.82 to 1.33 & 1.55 & 1.24 to 1.93 \\
\hline \multicolumn{9}{|l|}{ Teachers: } \\
\hline $\begin{array}{l}\text { teachers don't help me if I need extra } \\
\text { help }\end{array}$ & 1.35 & 1.10 to 1.66 & 1.55 & 1.30 to 1.85 & 1.40 & 1.09 to 1.80 & 1.31 & 1.03 to 1.67 \\
\hline teachers don't treat students fairly & 1.71 & 1.40 to 2.09 & 1.72 & 1.45 to 2.04 & 1.54 & 1.21 to 1.95 & 1.36 & 1.09 to 1.70 \\
\hline Combined teacher relations index & 1.60 & 1.28 to 2.01 & 1.84 & 1.51 to 2.24 & 1.74 & 1.32 to 2.30 & 1.52 & 1.16 to 2.00 \\
\hline \multicolumn{9}{|l|}{ School: } \\
\hline pupils ar & 2.26 & 1.69 to 3.03 & 1.64 & 1.25 to 2.17 & 1.76 & 1.36 to 2.29 & 1.55 & 1.21 to 1.99 \\
\hline the rules at our school are not fair & 1.41 & 1.16 to 1.72 & 1.53 & 1.29 to 1.81 & 1.74 & 1.37 to 2.20 & 1.52 & 1.22 to 1.89 \\
\hline don't feel safe at school & 2.67 & 2.19 to 3.27 & 3.64 & 3.04 to 4.35 & 2.45 & 1.92 to 3.11 & 3.79 & 3.01 to 4.76 \\
\hline don't feel I belong at my school & 1.32 & 1.08 to 1.62 & 1.77 & 1.48 to 2.11 & 1.52 & 1.18 to 1.96 & 1.85 & 1.45 to 2.35 \\
\hline are bullied weekly & 2.32 & 1.70 to 3.17 & 4.44 & 3.28 to 6.00 & 2.78 & 2.01 to 3.83 & 5.09 & 3.80 to 6.81 \\
\hline Combined school connections index & 2.49 & 2.00 to 3.08 & 3.41 & 2.80 to 4.15 & 2.70 & 2.12 to 3.43 & 3.00 & 2.39 to 3.77 \\
\hline
\end{tabular}

* $>2$ physical symptoms weekly. $\dagger>2$ psychological symptoms weekly. All predictors here used as dichotomous measures, - that is, odds ratios refer to risk of outcome in the exposed group compared with the unexposed group.

sense of belonging, safety, and bullying. Adolescent socioeconomic health inequalities were not strongly related to informal social relations with friends or communication with parents or teachers. Rather, it was relations with parents in regard to their participation in school, and perceptions of the school environment related to bullying and safety that were most strongly associated with adolescent health inequalities. The strong impact that aspects of school connectedness and sense of belonging may have on adolescents health has been described elsewhere. ${ }^{25} 3132$ Our findings are also consistent with a British study that showed social class inequalities in levels of parental encouragement for children's education at ages 7,11 , and $16 .{ }^{33}$

The high prevalence of self reported physical and psychological symptoms found in this study is consistent with findings elsewhere. ${ }^{12} 2833{ }^{34}$ Symptoms like those reported here will seldom be considered severe enough to warrant detailed diagnostic investigations, but they may lead to treatment by physicians, parents, or school nurses. Also, they can be important indicators of underlying health status that may track into adulthood. ${ }^{18} 19$ 36-38 Symptoms experienced by adolescents, however subjective, may influence their school attendance, and their academic and social development, with potential consequences for their adult socioeconomic position ${ }^{35}$ and should thus be considered potentially important indicators of adolescent health.

School is one of the first important social institutions in an adolescent's life and it appears that socioeconomic differences are already being reflected in their perceptions of how that institution functions for them. Recent discussions of social cohesion and social capital have tended to highlight the apparent positive role of more informal social affiliations for adult health. ${ }^{39}$ We found that for adolescents it was not so much their informal social affiliations with friends or the emotional support garnered through communications with parents, but social relations involving the parent-child-school triad, or what might be described as more formal, institutional linkages with the school that were most important in understanding inequalities in adolescent health. ${ }^{40}{ }^{41}$

In this study, we considered experiences of bullying a characteristic of the school environment, even though bullying clearly involves social relations with peers. We have found that bullying prevalence varies widely across schools in Denmark, ${ }^{22}$ and that the most effective interventions have been focused on the school rather than the individual level. ${ }^{42}$ Thus, bullying is less dependent on characteristics of individual adolescents, than it is on how adolescent groups function within the particular institutional environment created by the school.

Difficulties in general communication with parents showed little or no social patterning, which leads us to conclude that the lack of school involvement by socially disadvantaged parents should not be interpreted as scant interest in their children. However, lack of time seems unlikely to account for their lower engagement. Although perhaps not the case in all countries, lower social class parents in Denmark spend less time working than most higher class parents. ${ }^{43}$ Thus, it is difficult to understand these differences in involvement with 
Table 4 Age adjusted (Model 1) OR and 95\% Cl for physical symptoms and psychological symptoms by parents socioeconomic position (SEP), controlled for social relations indices for parents (Model 2), friends (Model 3), teachers (Model 4) and school (Model 5), and simultaneously for all indices combined (Model 6)

\begin{tabular}{|c|c|c|c|c|c|c|c|c|}
\hline \multirow{3}{*}{ Model 1} & \multicolumn{4}{|l|}{ Girls } & \multicolumn{4}{|l|}{ Boys } \\
\hline & \multicolumn{2}{|c|}{ Physical symptoms* } & \multicolumn{2}{|c|}{ Psychological symptoms $†$} & \multicolumn{2}{|c|}{ Physical symptoms* } & \multicolumn{2}{|c|}{ Psychological symptoms $†$} \\
\hline & & & & & & & & \\
\hline SEP I (high) & 1.0 & & 1.0 & & 1.0 & & 1.0 & \\
\hline SEP II (middle) & 0.94 & 0.73 to 1.20 & 0.96 & 0.78 to 1.19 & 1.35 & 0.99 to 1.82 & 1.12 & 0.84 to 1.49 \\
\hline SEP III (low) & 1.43 & 1.07 to 1.91 & 1.47 & 1.14 to 1.89 & 1.59 & 1.09 to 2.31 & 1.94 & 1.39 to 2.70 \\
\hline \multicolumn{9}{|l|}{ Model 2} \\
\hline SEP I (high) & 1.0 & & 1.0 & & 1.0 & & 1.0 & \\
\hline SEP II (middle) & 0.90 & 0.69 to 1.17 & 0.94 & 0.75 to 1.17 & 1.23 & 0.89 to 1.69 & 1.07 & 0.79 to 1.46 \\
\hline SEP III (low) & 1.36 & 1.00 to 1.85 & 1.38 & 1.05 to 1.81 & 1.32 & 0.87 to 1.99 & 1.60 & 1.11 to 2.31 \\
\hline Living with one adult & 1.14 & 0.87 to 1.50 & 1.06 & 0.83 to 1.34 & 1.25 & 0.91 to 1.73 & 1.01 & 0.74 to 1.38 \\
\hline Parental relations index & 2.49 & 1.92 to 3.24 & 3.10 & 2.44 to 3.94 & 1.92 & 1.40 to 2.63 & 2.45 & 1.83 to 3.29 \\
\hline \multicolumn{9}{|l|}{ Model 3} \\
\hline SEP I (high) & 1.0 & & 1.0 & & 1.0 & & 1.0 & \\
\hline SEP II (middle) & 0.93 & 0.72 to 1.20 & 0.98 & 0.79 to 1.22 & 1.17 & 0.85 to 1.62 & 1.05 & 0.78 to 1.42 \\
\hline SEP III (low) & 1.46 & 1.08 to 1.98 & 1.54 & 1.18 to 2.01 & 1.35 & 0.90 to 2.03 & 1.74 & 1.22 to 2.49 \\
\hline Living with one adult & 1.12 & 0.86 to 1.47 & 1.09 & 0.86 to 1.39 & 1.37 & 0.99 to 1.88 & 1.05 & 0.77 to 1.44 \\
\hline Friends relations index & 0.99 & 0.79 to 1.25 & 1.98 & 1.63 to 2.40 & 0.97 & 0.72 to 1.29 & 1.43 & 1.10 to 1.84 \\
\hline \multicolumn{9}{|l|}{ Model 4} \\
\hline SEP I (high) & 1.0 & & 1.0 & & 1.0 & & 1.0 & \\
\hline SEP II (middle) & 0.91 & 0.70 to 1.18 & 0.97 & 0.77 to 1.21 & 1.21 & 0.87 to 1.67 & 1.06 & 0.78 to 1.44 \\
\hline SEP III (low) & 1.43 & 1.05 to 1.94 & 1.52 & 1.17 to 1.99 & 1.38 & 0.92 to 2.07 & 1.80 & 1.25 to 2.58 \\
\hline Living with one adult & 1.16 & 0.89 to 1.52 & 1.11 & 0.88 to 1.40 & 1.28 & 0.92 to 1.77 & 1.04 & 0.76 to 1.43 \\
\hline Teacher relations index & 1.72 & 1.34 to 2.21 & 1.90 & 1.52 to 2.36 & 1.73 & 1.26 to 2.38 & 1.66 & 1.22 to 2.25 \\
\hline \multicolumn{9}{|l|}{ Model 5} \\
\hline SEP I (high) & 1.0 & & 1.0 & & 1.0 & & 1.0 & \\
\hline SEP II (middle) & 0.91 & 0.70 to 1.18 & 0.94 & 0.75 to 1.18 & 1.16 & 0.84 to 1.60 & 1.00 & 0.74 to 1.36 \\
\hline SEP III (low) & 1.28 & 0.94 to 1.74 & 1.30 & 0.99 to 1.72 & 1.11 & 0.73 to 1.68 & 1.47 & 1.02 to 2.12 \\
\hline Living with one adult & 1.09 & 0.83 to 1.43 & 1.04 & 0.82 to 1.32 & 1.24 & 0.90 to 1.72 & 0.98 & 0.71 to 1.34 \\
\hline School relations index & 2.55 & 2.00 to 3.25 & 3.30 & 2.64 to 4.13 & 2.78 & 2.09 to 3.70 & 3.12 & 2.39 to 4.07 \\
\hline \multicolumn{9}{|l|}{ Model 6} \\
\hline SEP I (high) & 1.0 & & 1.0 & & 1.0 & & 1.0 & \\
\hline SEP II (middle) & 0.82 & 0.63 to 1.08 & 0.87 & 0.69 to 1.10 & 1.07 & 0.77 to 1.50 & 0.95 & 0.69 to 1.30 \\
\hline SEP III (low) & 1.17 & 0.85 to 1.61 & 1.21 & 0.91 to 1.62 & 1.13 & 0.74 to 1.73 & 1.33 & 0.90 to 1.96 \\
\hline Living with one adult & 1.07 & 0.81 to 1.42 & 1.03 & 0.80 to 1.32 & 1.17 & 0.83 to 1.64 & 0.95 & 0.68 to 1.33 \\
\hline Parental relations index & 2.23 & 1.70 to 2.94 & 2.56 & 1.98 to 3.31 & 1.71 & 1.22 to 2.38 & 2.17 & 1.59 to 2.97 \\
\hline Friends relations index & 0.89 & 0.70 to 1.13 & 1.87 & 1.52 to 2.30 & 0.89 & 0.66 to 1.20 & 1.31 & 0.99 to 1.72 \\
\hline Teacher relations index & 1.25 & 0.95 to 1.64 & 1.35 & 1.06 to 1.71 & 1.30 & 0.93 to 1.84 & 1.11 & 0.79 to 1.55 \\
\hline School relations index & 2.15 & 1.65 to 2.79 & 2.64 & 2.08 to 3.36 & 2.36 & 1.74 to 3.20 & 2.61 & 1.96 to 3.48 \\
\hline
\end{tabular}

school, but they may reflect alienation from the school system, partly based on socially disadvantaged parents' own experiences at school. If so, then this may represent another mechanism through which social and health disadvantage are transmitted across generations.

The strength of this study is the large representative sample, the high response rate, and the widely used and internationally tested measures. As data are sampled during a school lesson only $2 \%$ of the pupils actually present end up being non-responders. Although children not attending school the day of the survey may introduce a response bias, compared with mailed surveys in the same age group, we have pupils with low socioeconomic position included in our population. ${ }^{2}$ The level of missing data on parental occupation in this study is $12 \%$, which is lower than most comparable studies. ${ }^{3}$ The missing data may lead to a selection bias, as the non-response may be associated with low socioeconomic position. However, the social class distribution in our population correspond closely to age specific national figures, and any selection bias would most probably lead us to underestimate social differences rather than overestimate them. ${ }^{44}{ }^{45} \mathrm{~A}$ recent study showed that childrens' reports of parental social class are valid. ${ }^{45}$ Also we know from analyses and focus group interviews that social class information in this survey is espe- cially valid for social class I and V in which the occupational terminology is fairly unequivocal: in social class I, for example, "medical doctor", "lawyer", "managing director", in social class V, for example, "lorry driver" or "factory worker" , and among economically inactive, for example, "disability pensioner" or "unemployed". There may however be problems in the specific classification of social class II, III, and IV, because of potential overlap and less clear terminology.

The study used self reported data and biased estimates of association because of reporting bias is a risk. It is probable that children reporting high symptom levels would also report relational problems. However, we think it is unlikely that this bias should affect the children's report of parental occupation and employment status. Also the variability of associations reported here suggest that the results are not just attributable to reporting bias. For example, relations with friends were not associated with physical symptoms for both genders, while relations with teachers showed strong associations with physical symptoms for both genders. However, none of these types of relations statistically explained socioeconomic differences in physical symptoms. Other types of relations-that is, relations with parents and school-showed strong associations with physical symptoms and explained much of the socioeconomic difference in physical symptoms. 
While this study is cross sectional, the temporal relation between exposure and outcome is reasonably clear. Presumably the parents have established an occupation prior to the child reporting symptoms. While it is possible that poor health of the child-and higher prevalence of reported symptomsaffects parental occupation, the magnitude of this effect is unlikely to be strong enough or variable enough to generate the strength and particular socioeconomic patterns of social relations and symptoms reported here. Nevertheless, longitudinal studies are needed to examine whether working class experience at school transmits from one generation to another, and whether these experiences lead to later health disadvantage among children.

We have shown how patterns of parent-child-school social relations were most important in understanding inequalities in physical and psychological symptoms in adolescence. However subjective these self reported symptoms may be, they appear to reflect some underlying processes whereby adolescents from poorer homes perceive lower parental support for school and lower chances of fitting into their school environment, and may be part of the cascade of early life influences that can lead to later social and health disadvantage.

\section{Authors' affiliations}

P Due, B Holstein, Department of Social Medicine, Institute of Public Health, University of Copenhagen, Denmark

J Lynch, Department of Epidemiology, School of Public Health, University of Michigan, USA

J Modvig, International Rehabilitation Council for Torture Victims, Copenhagen, Denmark

Funding: the study was supported by the Health Insurance Fund in Denmark (i.nr.: 11/216-98) and The Danish Ministry of Health (5.kt.j.nr.: 1999-524/04-20). John Lynch was supported by a grant from the National Institute of Health (5 RO1 HD35 120-02). This work was also supported by the European Science Foundation Program on Social Variations in Health.

\section{Conflicts of interest: none declared.}

\section{REFERENCES}

1 Ford G, Ecob R, Hunt K, et al. Patterns of class inequality in health through the life span: class gradients at 15,35 and 55 years in the west of Scotland. Soc Sci Med 1994;39:1037-50.

2 Holstein BE, Ito H, Due P. Social inequalities in child health status. [In Danish]. Ugeskr Laeger 1990;151:2910-13.

3 Goodman E. The role of socioeconomic status gradients in explaining differences in US adolescents' health. Am J Public Health 1999:89:1522-8.

4 West P, Macintyre S, Annandale E, et al. Social class and health in youth: findings from the west of Scotland twenty-07 study. Soc Sci Med 1990;30:665-73.

5 Macintyre S, West P. Lack of class variation in health in adolescence: an artefact of an occupational measure of social class? Soc Sci Med 1991;32:395-402

6 Rahkonen O, Lahelma E. Gender, social class and illness among young people. Soc Sci Med 1992;34:649-56.

7 Glendinning A, Love JG, Hendry LB, et al. Adolescence and health inequalities: extensions to Macintyre and West. Soc Sci Med 1992;35:679-87.

8 Rahkonen O, Arber S, Lahelma E. Health inequalities in early adulthood: a comparison of young men and woman in Britain and Finland. Soc Sci Med 1995:41:163-71.

9 Shiapush $M$, Singh GK. A multivariate analysis of the association between social class of origin and current social class with self-rated general health and psychological health among 16-year-old Australians. Aust N Z J Med 2000;30:653-9.

10 Lynch JW, Kaplan GA, Shema SJ. Cumulative impact of sustained economic hardship on physical, cognitive, psychological, and socia functioning. N Engl J Med 1997;337:1889-95.

11 Davey Smith G, Gunnell D, Ben-Shlomo Y. Lifecourse approaches to socioeconomic differentials in cause-specific adult mortality. In: Leon D, Walt G, eds. Poverty, inequality and health. Oxford: Oxford University Press, 2000.

12 Sweeting $\mathbf{H}$, West $P$. Health at age 11 : reports from schoolchildren and their parents Arch Dis Child 1998;78:427-34.

13 Siersted HC, Boldsen J, Hansen HS, et al. Population based study of risk factors for underdiagnosis of asthma in adolescence: Odense schoolchild study. BM 1998;316:651-5.
14 Eggen AE. The Tromso Study: frequency and predicting factors of analgesic drug use in a free-living population (12-56 years). J Clin Epidemiol 1993;46:1297-304.

15 Holstein B. Hansen EH, Due $P$, et al. Medicine use among 11 - to 15-year old girls and boys in Denmark 1988-1998. Scand J Public Health (in press)

16 Hansen EH, Holstein BE, Due P, et al. Medicine use among 11-15-year-old girls and boys: cross-sectional survey in 28 countries. Ann Pharmacother 2003;37:361-6.

17 Mortensen PB, Agerbo E, Erikson T, et al. Psychiatric illness and risk factors for suicide in Denmark. Lancet 2000;355:9-12.

18 Doris A, Ebmeier K, Shajahan P. Depressive illness. Lancet 1999:354:1369-75.

19 Hotopf, Mayou R, Wadsworth M, et al. Childhood risk factors for adults with medically unexplained symptoms: Results from a national birth cohort study. Am J Psychiatry 1999;11:1796-800.

20 Fearon $\mathbf{P}$, Hotopf $M$. Relation between headache in childhood and physical and psychiatric symptoms in adulthood: national birth cohort study. BM 2001;302:1145.

21 Williams K, Chambers M, Logan S, et al. Association of common health symptoms with bullying in primary school children. $B M$ 1996:313:17-19.

22 Due EP, Holstein BE, Jorgensen PS. Bullying as health hazard among school children [In Danish]. Ugeskr Laeger 1999;161:2201-6.

23 Forero R, McLellan L, Rissel C, et al. Bullying behaviour and psychosocial health among school students in New South Wales, Australia: cross sectional survey. BM 1999;319:344-8.

24 Nansel TR, Overpeck M, Pilla RS, et al. Bullying behaviors among US youth. Prevalence and association with psychosocial adjustment. JAMA 2001;285:2094-100.

25 Resnick MD, Bearman PS, Blum RW, et al. Protecting adolescents from harm. Findings from the National Longitudinal Study on Adolescent Health. JAMA 1997;278:823-32.

26 Kaltiala-Heino R, Rimpela M, Marttunen M, et al. Bullying, depression, and suicidal ideation in Finnish adolescents: school survey. BM 1999;319:348-51

27 Seidman E, Chesir-Teran D, Friedman JL, et al. The risk and protective functions of perceived family and peer microsystems among urban adolescents in poverty. Am J Community Psychol 1999;27:211-37.

28 Kessler RC, Davis CG, Kendler KS. Childhood adversity and adult psychiatric disorder in the US National Comorbidity Survey. Psychol Med 1997; 27:1101-19.

29 Currie C, Hurrelmann K, Settertobulte W, et al. Health and health behaviour among young people. Health behaviour in school-aged children: a WHO cross-national study (HBSC). International report 1 1-132. No 1 in Series: Healthy policy for children and adolescents. Copenhagen: World Health Organization, 2000.

30 Hetland J, Torsheim T, Aaroe LE. Subjective health complaints in adolescence: dimensional structure and variation across gender and age. Scand J Public Health 2002;30:223-30.

31 Vingilis $\mathbf{E}$, Wade TJ, Adlaf $E$. What factors predict student self-rated physical health. J Adolesc 1998;21:83-97.

32 Bonny AE, Britto MT, Klostermann BK, et al. School disconnectedness: identifying adolescents at risk. Pediatrics 2000;106:1017-21.

33 Power C, Matthews S. Origins of health inequalities in a national population sample. Lancet 1997;350:1584-9.

34 Due $\mathbf{P}$, Holstein BE, Marklund U. Self-reported health status among students in Scandinavia. Nord Med 1991;106:71-4.

35 Poikolainen K, Kanerva R, Lonnqvist J. Life events and other risk factors for somatic symptoms in adolescence. Pediatrics 1995;96:59-63.

36 Wadsworth MEJ. Serious illness in childhood and its association with later life achievement. In: Wilkinson RG, ed. Class and health: research and longitudinal data. London: Tavistock, 1986

37 Hotopf M, Carr S, Mayou R, et al. Why do children have chronic abdominal pain, and what happens to them when they grow up? Population based cohort study. BM 1998;316:1 196-200.

38 Mortimer MJ, Kay J, Jaron A, et al. Does a history of maternal migraine or depression predispose children to headache and stomach-ache? Headache 1992;32:353-5.

39 Wilkinson RG. Unhealthy societies. The afflictions of inequality. London: Routledge, 1996.

40 Lynch JW. Income inequality and health: expanding the debate. Soc Sci Med 2000;51:1000-4

41 Lynch J, Due P, Muntaner C, et al. Social capital-is it a good investment strategy for public health? J Epidemiol Community Health 2000;54:404-8.

42 Olweus D. Bullying at school: basic facts and effects of a school based intervention program. J Child Psychol Psychiatry 1994;35:1171-90.

43 Andersen D, Hestbaek A-D. Responsibility and values. A survey of families with children. [In Danish]. Copenhagen: National Institute of Social Research, 1999.

44 Goodman E, Amick BC, Rezendes MO, et al. Adolescents' understanding of social class: a comparison of white upper middle class and working class youth. J Adolesc Health 2000;27:80-3.

45 West $\mathbf{P}$, Sweeting $H$, Speed $E$. We really know what you do: a comparison of reports from 11 year olds and their parents in respect of parental economic activity and occupation. Sociology 2001;35:539-60. 